\title{
Natural Disaster Relief Management Using Dynamic Key Algorithm in Cloud Environment
}

\author{
Dr. G. Ravi Kumar, Dr. S. Gunasekaran, Muthu Kumar P, \\ Sanjay R, Jom Sebastian, Vasanth Kumar K
}

\begin{abstract}
Natural disaster is happening all around the world with vulnerable effects to life and property. The disaster occurred in Chennai and Kerala cause severe effects and there arise a necessity for developing a New Internet based Android application that provides a platform for donating basic necessary items like food, clothes etc.., to all needy people/organizations. The number of smart phone users are increased thus the disaster management system was implemented as a smart phone application. During the period of disaster, the activity relief is not well-coordinated. For the efficient provision of rescue and relief to disaster -affected areas, this system has been developed. The disaster management system Android application determines the optimum route using geographical locations that help the volunteers and rescuers to serve the most number of people who affected in the disaster area at shortest possible time. Dynamic key algorithm was applied for secured cloud environment and geographic location were accessed by the Google Map service.

Index Terms - Android disaster management, Dynamic key algorithm, Google Maps service, Core Java.
\end{abstract}

\section{INTRODUCTION}

The Android based application is developed from the after effects of floods occurred in Chennai on Dec 2015, Kerala flood on august 2018 and recently occurred disaster in Delta regions of Tamil Nadu are very few among them. Thou there were volunteers as helping hands it was not in an efficient manner and this application makes it more efficient by reaching to every nuke and corners and manage demand and supply effectively. This Android application consist of helpprovider module, help seeker module, and volunteer list. This application provides a platform for donating basic necessary requirements to the victims as per the requisition made by the people, which is provided only after the confirmation made by our volunteers.

\section{EXISTING SYSTEM}

People donate stuff manually by visiting each disaster affected areas number of times. Efforts are made to help

Dr. G. Ravi Kumar, Department of CSE, Coimbatore Institute of Engineering and Technology, Coimbatore, India

Dr. S. Gunasekaran, Department of CSE, Coimbatore Institute of Engineering and Technology, Coimbatore, India

Muthu kumar P, Department of CSE, Coimbatore Institute of Engineering and Technology, Coimbatore, India

Sanjay R, Department of CSE, Coimbatore Institute of Engineering and Technology, Coimbatore, India

Jom Sebastian, Department of CSE, Coimbatore Institute of Engineering and Technology, Coimbatore, India

Vasanth kumar K, Department of CSE, Coimbatore Institute of Engineering and Technology, Coimbatore, India people donate their surplus food to shelters through their official website, wherein people can donate food, donate funds and also volunteer for various activities. But here comes the problem of wastage of food and necessary items due to the absence of an efficient system. The relief activity becomes difficult without knowing the exact requirements of affected people.

\section{PROPOSED SYSTEM}

\section{A. DISASTER MANAGEMENT}

The disaster management has four phase: mitigation phase, preparedness phase, response phase, and recovery phase. Mitigation phase: It is the attempt to reduce disaster risks by focusing on long-term measures of eliminating disasters. Preparedness phase: It is the development of an action plan for an upcoming disaster. Response phase: It is the mobilization of services and relief when disaster strikes Recovery phase:It is the restoration of the affected area to its previous state.

\section{B. USING WIRELESS MOBILE TECHNOLOGIES}

The wide coverage of the mobile phone network may be used in the implementation of a disaster management system making it available in everyone's pocket. . Results showed that mobile technology may be used to disseminate pre-disaster warnings and post-disaster announcements, to receive information about relief needs, and to exchange information about health hazard. Also, in disaster information management, geographic locations of those in need is important. Using their mobile phones, locations can either be determined using the mobile network system or through the use of an integrated Global Positioning System (GPS) included in their phone.

\section{ANDROID MOBILE ENVIRONMENT}

There are a number of mobile developmentenvironments in the market. One of which is Android created by the Open Handset Alliance. Android is an openand comprehensive platform for mobile devices. It is designed to be more open than other mobile operating manufacturers will be able to make new products faster and at a much lower cost. The end result will be a more personal and more flexible experience to the user. For this reason, themobile development environment was used in the implementation of the disaster management system. 


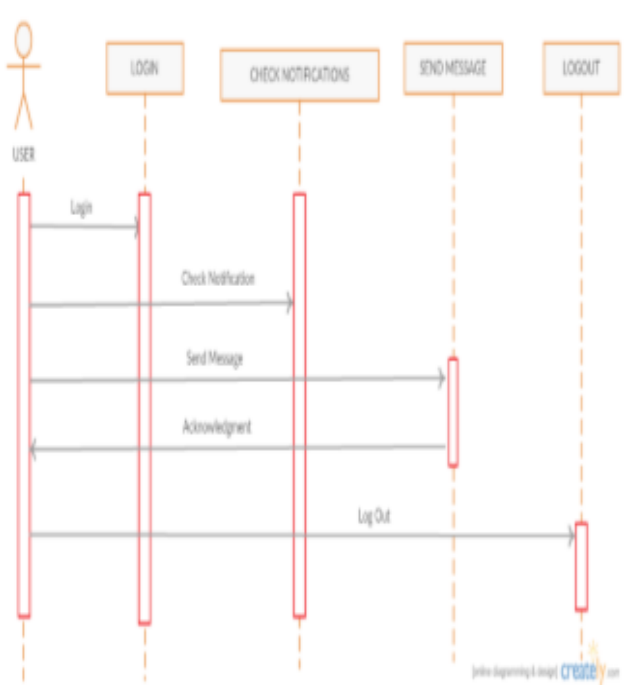

Fig.1. Flow chart for file encryption

\section{DYNAMIC KEY ALGORITHM}

Dynamic Key Generation Algorithm for User Authentication at Mobile Cloud Environment. The point of this paper is to execute a validation arrangement, which can be utilized in cloud administrations. The validation technique will be two-point confirmation with a cell phone as a verification gadget, that unscrambles the key (sent to customer portable) which is produced by key generator which is substantial one time for a specific measure of time. Distributed computing can possibly turn into a pioneer in advancing a protected, virtual and financially doable IT arrangement and future work and advancement lies in institutionalizing Cloud registering security conventions. In this paper we have built up a client validation calculation which gives an onetime secret phrase, for a client to gain admittance to the cloud server.

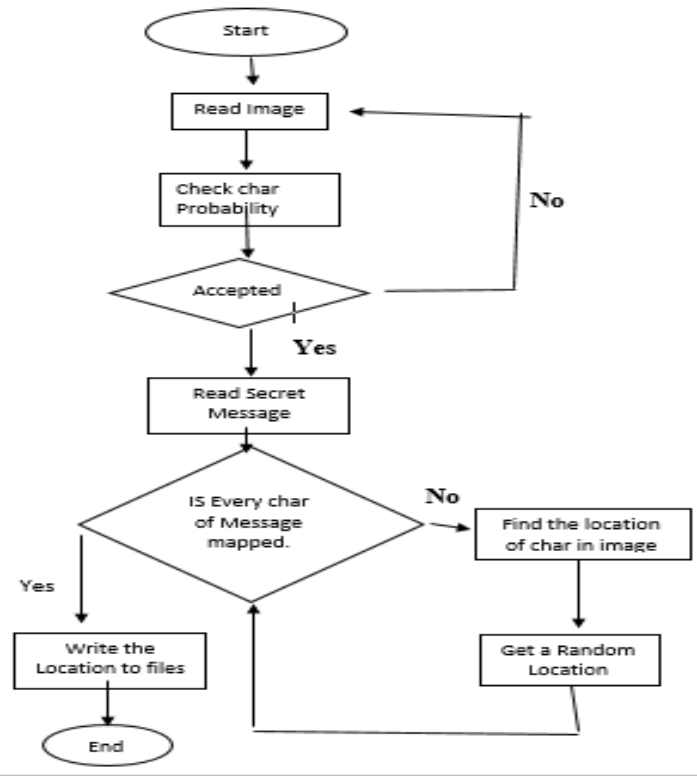

Fig.2. Flow chart for file encryption

\section{GEOLOCATIONS}

First, geographic locations of people in need are set. There are two ways that geographic locations can be set: using the application integrated with this app known as Google Map or sending location via text or short message service (SMS). Geographic locations or geolocations are described in latitude and longitude. By using the Google Map services, the volunteers will came to known the location of the people who are in need. The help seeker can upload their location using Google map services to this Android application.

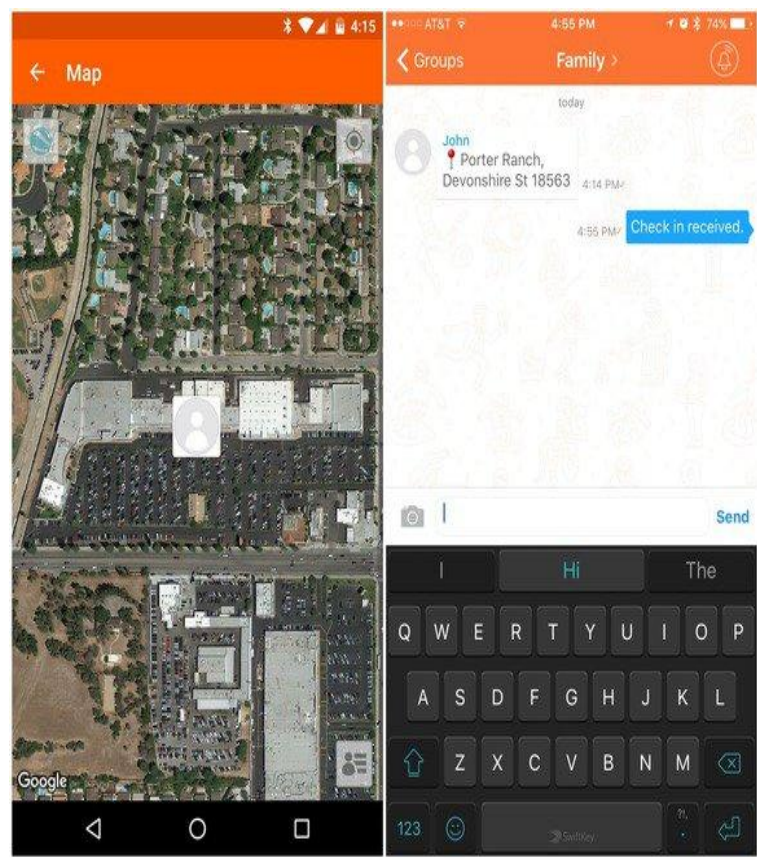

Fig.3.GPS Location

\section{IMPLEMENTATION}

These are some of the screen of our developed application. First screen shows the homepage of the developed Android application which contains the help providers tab, help seekers tab and volunteer list. Second screen shows the list of requirements available for the affected people with upload button. Third screen shows the list of volunteers with their location.

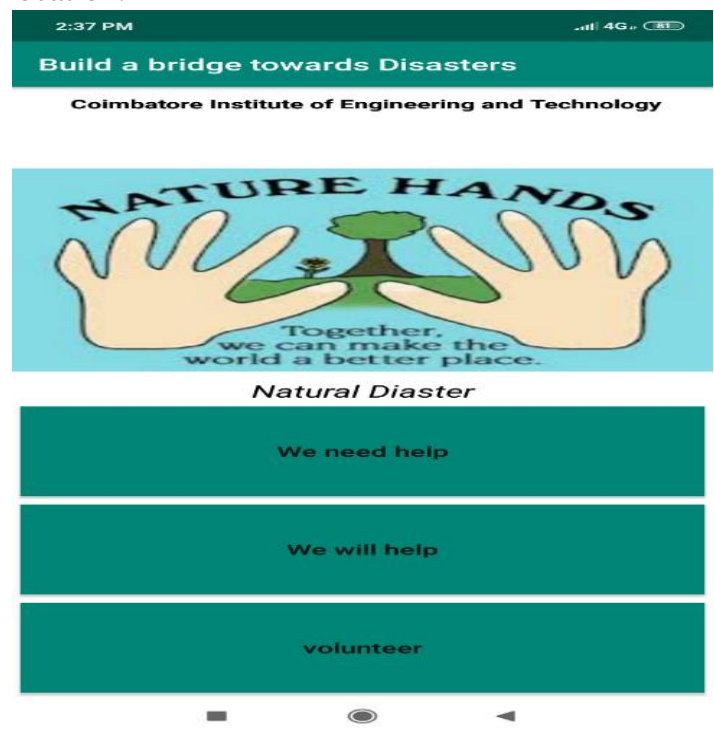

Fig.4. Home page of the application 


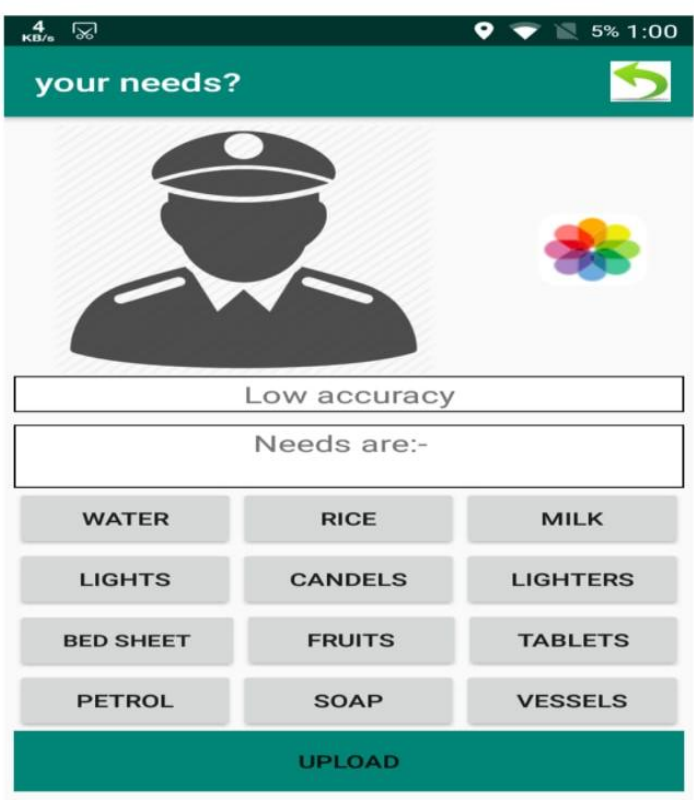

Fig.5. Screen for requirements uploading.

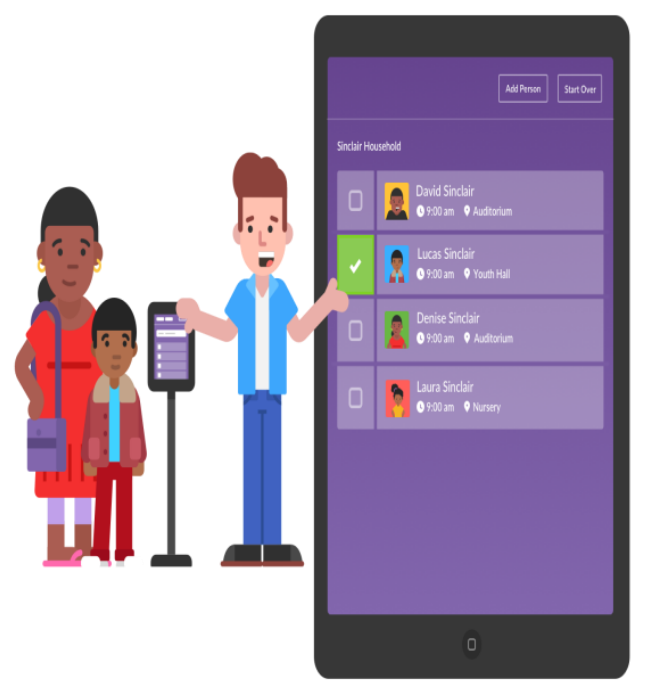

Fig.6. Screen for volunteer list

VII. CONCLUSION

Use italics for emphasis; The disaster management system that facilitates the logistics for the rescue and relief operations during a disaster was implemented in an Androidbased mobile phone. Geographic locations of the people in need were sent via Google Map to this Android application. This service provides the information about the location of the place where the people are in emergency and what's the possibilities. This system is flexible because it allows the prioritization to be changed. This disaster relief management Android application that can be used during the response phase in a disaster especially when time is crucial.

\section{REFERENCES}

[1] F. Chen, R. Chang, W. Lin, S. H. Chen, Y. C. Chen and C. N. Li, "Disaster and Emergency Management System," The 15th International Symposium on Wireless Personal Multimedia Communications, Taipei, 2012, pp. 363-368.

[2] Benkhelifa, N. Nouali-Taboudjemat and S. Moussaoui, "Disaster Management Projects Using Wireless Sensor Networks: An Overview," 2014 28th International Conference on Advanced Information Networking and Applications Workshops, Victoria, BC, 2014, pp. 605-610.

[3] S. Moussaoui, "Disaster Management Projects Using Wireless Sensor Networks: An Overview," $201328^{\text {th }}$ International Conference on Advanced Information Networking and Applications Workshops, Victoria, BC, 2013, pp. 363-368. 